\title{
Thrombolysis and thrombectomy as an effective treatment for ischemic cerebral circulation disorders
}

\author{
N.H. Ngoc ${ }^{1,2}$, N.V. Thong ${ }^{1,2}$ and N.Q. An ${ }^{1,2}$ \\ ${ }^{1}$ Phu Tho General Hospital, Viet Nam \\ ${ }^{2}$ Vietnam Stroke Association \\ Corresponding author: N.Q. An \\ E-mail: longdangtrang@gmail.com
}

Genet. Mol. Res. 20 (1): gmr18740

Received December 30, 2019

Accepted April 20, 2020

Final Revision January 25, 2021

Published March 29, 2021

DOI http://dx.doi.org/10.4238/gmr18740

\begin{abstract}
The number of stroke cases has more than doubled worldwide over the past four decades, including in low- and middleincome countries. Therefore, understanding the present situation of acute ischemic stroke in Vietnam is an urgent theme. The number of stroke cases in Vietnam is correlated with and reflected in the number of thrombolysis and thrombectomies performed. To increase the effectiveness of stroke treatment, use of thrombolysis and thromboembolism alone are insufficient. New organizational models for emergency care and methodologies for identifying the first signs of stroke need to be developed. We conducted a retrospective study of reports from 29 clinics that used these two types of treatment in 2009-2017. In the 50 stroke units, departments, and stroke centers in Vietnam, about 640 beds are designed to potentially receive and treat a population of 93 million people. Among the 1145 patients who were treated with recombinant tissue plasminogen activator, they had a National Institutes of Health Stroke Score (NIHSS) medium score when admitted to the hospital: 14.1; modified Rankin Scale (mRS) post three months: mRS (0-1) was $52.2 \%$, mRS (6 score) was $6.12 \%$. Intracranial hemorrhage rate was $4.1 \%$. Of the 269 patients treated with thrombectomy, the mean age was $62.14 \pm 13.3$; NIHSS medium
\end{abstract}


score entreat admission to the hospital: $16.2 \pm 7.85$; complete recanalization after treatment (TICI score $2 \mathrm{~b}-3$ ) was $60.3 \%$. The rate of functional independence ( 90 day $\mathrm{mRS}$ score of 0 - 2) was 34.6\%; the death rate was $17.9 \%$; intracranial hemorrhage and symptomatic hemorrhage rate was $22.5 \%$ and $10.1 \%$, respectively. Thrombolysis and thrombectomy are important treatments that can reduce disability (not mortality) in some patients after acute ischemic stroke; however, it is necessary to introduce higher quality and safe services. For this purpose, a better integrated approach to stroke care in Vietnam needs to be developed.

Key words: Acute ischemic stroke; NIHSS score; mRS score; Thrombolysis; Thrombectomy

\section{INTRODUCTION}

Acute ischemic stroke (AIS) is an urgent problem of modern healthcare at the world level, since it is accompanied by high rates of mortality and disability as a result and complication of this pathology (Brott and Bogousslavsky, 2000; Mukherjee and Patil 2011; Leng and Xiong, 2019). This, in turn, leads to increased economic costs for individual states due to reduced performance or loss of performance in this category of patients (Van Exel et al., 2005; Dawson et al., 2007 Henriksson et al., 2010). Consequently, AIS is accompanied by significant clinical consequences, social and economic losses, which determines the urgency of the problem and justifies the need for significant theoretical and practical efforts and innovations, improvement of therapeutic, diagnostic and preventive measures for this disease (Deb et al., 2010). The share of AIS accounts for the largest number of cases of acute cerebrovascular accident - more than $85 \%$.

Ischemic pathogenetically caused by sudden obstruction of blood vessels in the brain. Hemorrhagic stroke is observed in $10-15 \%$ of cases of acute cerebrovascular accident. The blood poured out of the vessel causes compression of the brain tissue, which, as a result, is the cause of subsequent complications. The current problem is the low awareness of the population about the causes of the clinical manifestations of stroke. Only a third of stroke patients are aware of a history of stroke (Leng and Xiong, 2019).

Immediate reperfusion is key to maintaining the integrity and function of the brain. Intravenous infusion of recombinant tissue plasminogen activator (rt-PA) and endovascular thrombectomy significantly improve the chances of recovery without subsequent disability, as proven in various studies (El Tawil and Muir, 2017). Thrombolysis is the first-line therapy if treatment is started within no more than 4.5 hours after the onset of symptoms. It should be borne in mind that the positive effect of alteplase correlates with the time from the onset of the first symptoms, therefore, the need for early use of thrombolytic therapy is obvious. Alteplase should be used even if further mechanical thrombectomy is possible (Molina and Saver, 2005; Prabhakaran et al., 2015). However, the frequency of recanalization with rt-PA is rather low, especially in occlusion of large vessels: $14 \%$ for the internal carotid artery and 55\% for occlusion of the middle cerebral artery. (Balami et al., 2015). The use of rt-PA is also associated with a significant number of side effects and 
contraindications (Wijdicks et al., 2006). In addition, the latter technique necessarily requires early application after the onset of symptoms (Wang et al., 2015).

Endovascular thrombectomy is considered an alternative to thrombolysis and has a high level of evidence base. However, two issues may limit the widespread clinical use of mechanical thrombectomy. First, only an estimated $10 \%$ of patients with AIS have a proximal large artery occlusion in the anterior circulation and present early enough to qualify for mechanical thrombectomy within 6 hours, while approximately $9 \%$ of patients presenting in the 6-to-24-hour time window may qualify for mechanical thrombectomy. Second, only a few stroke centers have sufficient resources and expertise to deliver this therapy (Palaniswami and Yan, 2015; Alawieh et al., 2018; Watanabe et al., 2019). The result of a number of studies demonstrates a clear advantage of the combined use of mechanical thrombectomy using a stent retriever in combination with pharmacological thrombolysis, especially in occlusion of large cerebral vessels and their branches (Guedin et al., 2015; Coutinho et al., 2017).

According to statistics, the level of disability and mortality from AIS is steadily increasing in countries with an unstable economic situation, with low and middle income (Nguyen et al., 2010; Tirschwell et al., 2012; Pham et al., 2016). According to data provided by the World Health Organization, by 2030, noncommunicable diseases could be the cause of $75 \%$ of total global deaths (World Health Organization, 2005). Over the past 40 years, the incidence and mortality rates from AIS in developed countries have decreased by $42 \%$, while in low- and middle-income countries, the corresponding rates have more than doubled (Avan et al., 2019). Nearly $90 \%$ of all AIS deaths occur in low- and middleincome countries (Strong et al., 2007). Considering all of the above, the aim of this study was to analyze the current situation in the treatment of AIS using thrombolysis, as well as thrombectomy methods and / or their combination in Vietnam.

\section{MATERIAL AND METHODS}

\section{Subjects}

We included 1145 patients given rt-PA (doses 0.9 and $0.6 \mathrm{mg} / \mathrm{kg}$ body weight) and 269 patients treated with rt-PA and then had thromboectomy from $2009-2017$. The study was approved by our institutional ethics in human research committee.

\section{Methods}

According to the meta-analysis of the statistical reports of hospitals using these two treatments, the results obtained are averaged and a percentage. The data were analyzed using statistical methods, SPSS version 22, EZR version 1.38. To present the typical result for nominal qualitative variables, the mode of indicators, interval estimation of dichotomous variables, were used. When making multiple comparisons between groups, we used the Chisquare test with Bonferroni correction.

\section{RESULTS AND DISCUSSION}

Currently, there are about 50 centers, departments and units with about 650 beds in Vietnam for this type of patient (Table 1). By region of the country: North: 360 beds / 23 
units, Middle: 70 beds / 7 units, and South: 220 beds / 16 units. This is 2.5 times less than in first-world countries, such as the UK (Table 2). In Vietnam, there are only 9 centers that can apply intervention therapy with the total budget per patient from USD 3000-4300. In addition, about 1000 - 1100 cases of AIS were treated duringtwo, years, which is in more than two times higher than in the UK.

Table 1. Stroke specialized units in Vietnam.

\begin{tabular}{lll}
\hline Hospital & Type of center & $\begin{array}{l}\text { Number of } \\
\text { beds per } \\
\text { center }\end{array}$ \\
\hline $\begin{array}{l}\text { Bach Mai Hospital; 103 Army Hospital (stroke } \\
\text { department) }\end{array}$ & 40 \\
$\begin{array}{l}\text { 108 Military Central Hospital } \\
\text { Thai Nguyen National Hospital; Cho Ray Hospital; }\end{array}$ & Stroke unit & 55 \\
$\begin{array}{l}\text { Phu Tho General Hospital } \\
115 \text { People's Hospital }\end{array}$ & Stroke center & 20 \\
\hline
\end{tabular}

Bac Ninh General Hospital; Quang Ninh General

Hospital; An Binh Hospital; Cao Bang General

Hospital; Gia Dinh People Hospital; Ha Giang

General Hospital; Thong Nhat Hospital; Tuyen

Quang General Hospital; Nguyen Tri Phuong

Hospital; Vinh Phuc General Hospital; Trieu An

Hospital; Nghe An General Hospital; Ninh Binh

General Hospital; 105 Army Hospital; Trung Vuong

Hospital; Thanh Hoa General Hospital; Friendship

Hospital; 175 Army Hospital; Ngoc Lac General

Hospital; Hue Central Hospital; Thu Duc General

Hospital; Ha Nam General Hospital; Da Nang

General Hospital; Dong Nai General Hospital;

Hung Yen General Hospital; National hospital of

obstetrics and gynecology; Tien Giang General

Hospital; Viet Tiep General Hospital; 17 Army

Hospital; Can Tho General Hospital; Thai Binh

General Hospital; Quang Nam General Hospital; Ho

Chi Minh City University of Medicine and

Pharmacy; Bac Giang General Hospital; Quy Nhon

General Hospital; An Giang General Hospital; Lang

Son General Hospital

Ninh Binh General Hospital

A total of 1145 patients were enrolled in eight centers for thrombolysis treatment and 269 patients in six centers for combining therapy (thrombolysis and thromboectomy) from June 2009 to October 2017 and constitute the study population. Table 3 shows their baseline demographic characteristics and time-to-treatment. Patients undergoing thrombectomy in combination with an intravenous thrombolysis, were, on average, older and they had more often hypertension, hyperlipidemia, and previous stroke, and more often atrial fibrillation.

The largest differences between groups involved stroke severity (NIHSS score) and vessel occlusion location. Patients in the thrombectomy groups had greater symptom severity and had internal carotid and M1 segment middle cerebral artery occlusions more frequently. Time to intravenous thrombolysis was not different between patients with an additional thrombectomy compared to those without.

On the 1145 patients, treated rt-PA had NIHSS medium score to enter hospital: 14.1 ; mRS post three months: mRS (0-1) was $52.2 \%$, mRS (6 score) was $6.12 \%$. 
Table 2. Current situation of thrombotic interventions in Vietnam and the United Kingdom (UK) National Institute for Health and Care Excellence Guideline (2016).

\begin{tabular}{|c|c|}
\hline Vietnam & UK \\
\hline $\begin{array}{l}\text { About } 50 \text { centers, departments and units with about } 650 \\
\text { beds }\end{array}$ & About 120 stroke centers \\
\hline $\begin{array}{l}\text { Nine hospitals that can intervene (108 Military Central } \\
\text { Hospital, Bach Mai Hospital, } 103 \text { Army Hospital, Phu } \\
\text { Tho General Hospital, Hue Central Hospital, } 115 \\
\text { People's Hospital, Cho Ray hospital, Ho Chi Minh } \\
\text { City University of Medicine and Pharmacy, Can Tho } \\
\text { General Hospital) }\end{array}$ & $\begin{array}{l}24 \text { centers that can } \\
\text { intervene }\end{array}$ \\
\hline Total of 20 intervention centers nationwide & $\begin{array}{l}\text { Total of } 82 \text { intervention centers } \\
\text { across the UK ( } 2 \text { in } \\
\text { Scotland and } 1 \text { in Wales })\end{array}$ \\
\hline $\begin{array}{l}\text { Budget for intervention has not been set yet, } \\
\text { depending on the patient, on average each case (from } \\
\text { from USD 3000-4300) }\end{array}$ & $\begin{array}{l}\text { Budget for interventions } \\
\text { through the Ministry of } \\
\text { Health has been agreed } \\
\text { since April } 2017 \text { - around } £ \\
12,000 \text { per case (VND } 350 \\
\text { million) }\end{array}$ \\
\hline $\begin{array}{l}\text { About } 1000 \text { - } 1100 \text { cases performed in } 2 \text { years (V115: } \\
\text { 500; BV108: 200, Bach Mai: 200; DRH: } 34 \text {; Cho Ray: } \\
\text { 40; V103: 10; Phu Tho: 6) }\end{array}$ & $\begin{array}{l}500 \text { cases were performed } \\
\text { in } 2016-2017\end{array}$ \\
\hline
\end{tabular}

Table 3. The results of treatment of venous thromboembolism (via rt-PA).

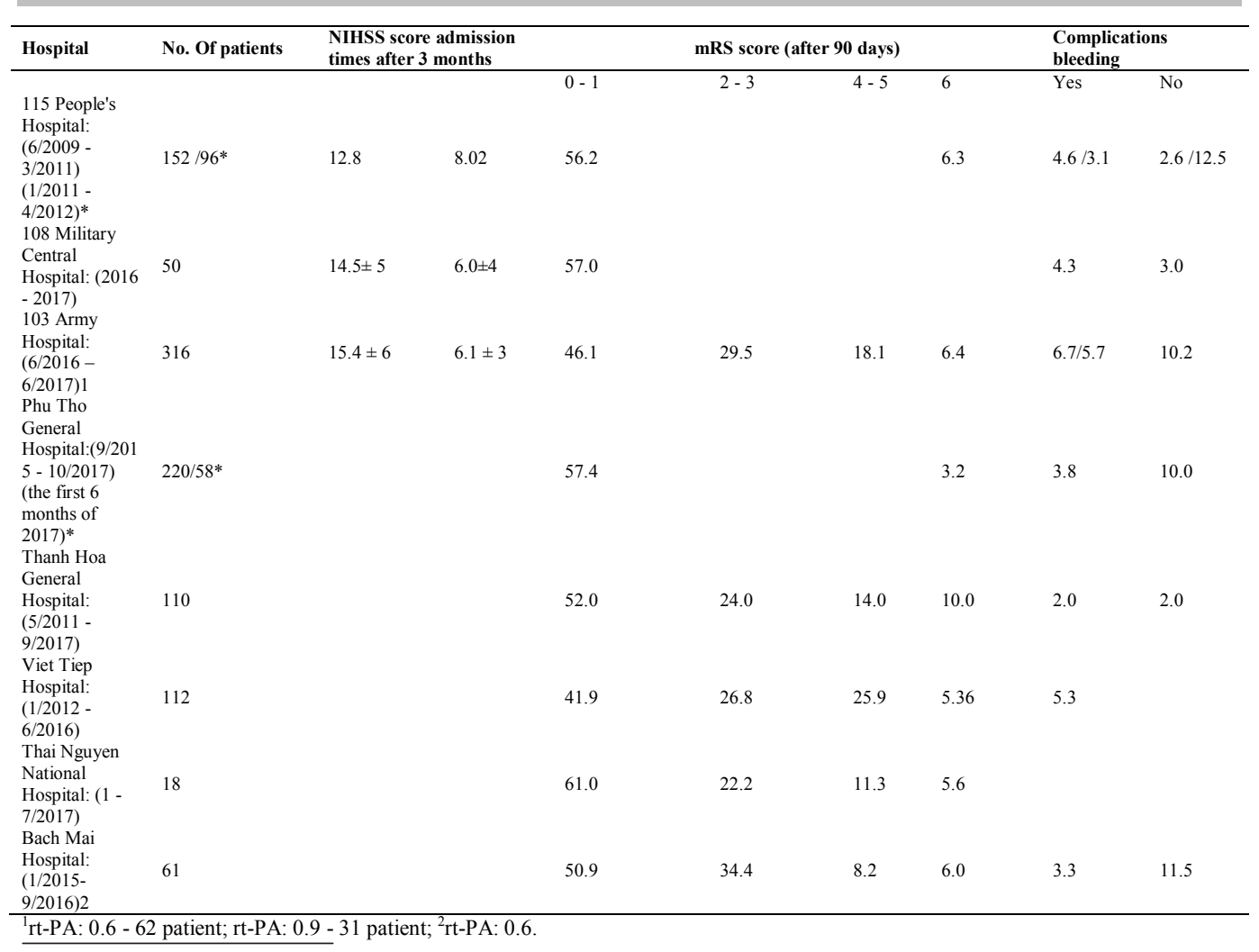

Genetics and Molecular Research 20 (1): gmr18740 
Intracranial hemorrhage rate was $4.1 \%$. On the 269 patients treated thromboectomy, the mean age was $62.14 \pm 13.3$; NIHSS medium score to enter hospital: $16.2 \pm 7.85$; complete recanalization after treatment (TICI score $2 \mathrm{~b}-3$ ) was $60.3 \%$. The rate of functional independence ( 90 day mRS score of $0-2$ ) was $34.6 \%$; the death rate was 17.9 $\%$; intracranial hemorrhage and symptomatic hemorrhage rate was $22.5 \%$ and $10.1 \%$.

In both methods of treatment (thrombolysis treatment and combining therapy thrombolysis and thromboectomy) complications bleeding was observed. In case of thrombolysis this factor was $4.6 \%$, where at combining therapy $-22.5 \%$. In addition, at rt$\mathrm{PA}+$ thromboectomy therapy other complications such as recurrent embolism was occred.

\section{Table 4. Treatment of thrombolytic method combined with thrombolysis.}

\begin{tabular}{llllllllll}
\hline Hospital & No. Of patie & The average & $\begin{array}{l}\text { NIHSS } \\
\text { score } \\
\text { admission }\end{array}$ & $\begin{array}{l}\text { complete } \\
\text { recanalization }\end{array}$ & $\begin{array}{l}\text { mRS (3 } \\
\text { months) }\end{array}$ & $\begin{array}{l}\text { Died, } \\
(\%)\end{array}$ & $\begin{array}{l}\text { Complicati } \\
\text { ons (\%) }\end{array}$ \\
\hline & & & $\begin{array}{l}\text { TIC I } \\
2 \mathrm{~b} / 3\end{array}$ & $\begin{array}{l}\text { TIC I } 0- \\
2\end{array}$ & $0-2$ & $3-5$ & A1 & B2 & C3
\end{tabular}

\section{Military}

Central

Hospital

(7/2016 -

6/2017); rt-

PA:6/138=18.9

$\%$

108 Military

Central

Hospital
$(1 / 2014$ -

(1/2014 -

PA:4/27 = 14.8

$\%$

115 People's

Hospital(4/2012

- $3 / 2013)$; rt-
PA: $21 / 36=$

$58.3 \%$

15 People's

Hospital and

Nghe An

General

Hospital:

(6/2016 -

4/2017); rt-

PA: $43 / 43=10$

$0 \%$

Bach Mai

Hospital:

(6/2015 -

5/2016); rt-
PA: $25 / 25=10$

$0 \%$

Mean

\section{CONCLUSIONS}

To optimize the diagnosis and treatment of acute cerebrovascular accidents in Vietnam, it will be necessary to develop and improve algorithms for providing emergency care. Only a small proportion of patients with appropriate indications receive thrombolytic therapy in a timely manner, which is due, among other things, to a low level of patient awareness of the symptoms of stroke and imperfect algorithms for first aid. The use of various innovative approaches to the diagnosis and treatment of strokes turned out to be ineffective, which shows the relevance of research and the neeed for new techniques in this area.

Genetics and Molecular Research 20 (1): gmr18740

CFUNPEC-RP www.funpecrp.com.br 


\title{
ACKNOWLEDGMENTS
}

The authors are thankful to Phu Tho General Hospital for financial support, and to Vietnam Stroke Association for expertise support.

\section{CONFLICTS OF INTEREST}

\author{
The authors declare no conflict of interest.
}

\section{REFERENCES}

Alawieh A, Chatterjee A, Feng W, Porto G, et al. (2018). Thrombectomy for acute ischemic stroke in the elderly: A 'real world' experience. J. Neurointervent. Surg.10: 1209-1217.

Avan A, Digaleh H, Di Napoli M, Stranges S, et al. (2019). Socioeconomic status and stroke incidence, prevalence, mortality, and worldwide burden: An ecological analysis from the global burden of disease study 2017. BMC Med. 17: 191.

Balami JS, Sutherland BA, Edmunds LD, Grunwald IQ, et al. (2015). A systematic review and meta-analysis of randomized controlled trials of endovascular thrombectomy compared with best medical treatment for acute ischemic stroke. Int. J. Stroke. 10(8): 1168-1178.

Brott T and Bogousslavsky J (2000). Treatment of acute ischemic stroke. N. Eng. J. Med. 343: 710-722.

Coutinho JM, Liebeskind DS, Slater L-A, Nogueira RG, et al. (2017). Combined intravenous thrombolysis and thrombectomy vs thrombectomy alone for acute ischemic stroke: A pooled analysis of the swift and star studies. JAMA Neurol. 74: 268-274.

Dawson J, Lees JS, Chang T-P, Walters MR, et al. (2007). Association between disability measures and healthcare costs after initial treatment for acute stroke. Stroke. 38: 1893-1898.

Deb P, Sharma S and Hassan K (2010). Pathophysiologic mechanisms of acute ischemic stroke: An overview with emphasis on therapeutic significance beyond thrombolysis. Pathophysiology. 17: 197-218.

Dewilde S, Thijs V, Annemans L, Peeters A., et al. (2014). Quality of life decrements after stroke. Value in Health. 17: A331.

El Tawil S and Muir KW (2017). Thrombolysis and thrombectomy for acute ischaemic stroke. Clin. Med. 17: 161.

Guedin P, Larcher A, Decroix J-P, Labreuche J, et al. (2015). Prior IV thrombolysis facilitates mechanical thrombectomy in acute ischemic stroke. J. Stroke Cerebrovasc. Dis. 24: 952-957.

Henriksson KM, Farahmand B, Johansson S, Åsberg S, et al. (2010). Survival after stroke - the impact of CHADS2 score and atrial fibrillation. Int. J. Cardiol. 141: 18-23.

Leng $\mathrm{T}$ and Xiong Z-G (2019). Treatment for ischemic stroke: From thrombolysis to thrombectomy and remaining challenges. Brain Circ. 5: 8.

Molina CA and Saver JL (2005). Extending reperfusion therapy for acute ischemic stroke: Emerging pharmacological, mechanical, and imaging strategies. Stroke. 36: 2311-2320.

Mukherjee D and Patil CG (2011). Epidemiology and the global burden of stroke. World Neurosurg. 76: 85-90.

National Institute for Health and Care Excellence Guideline (2016). Venous thromboembolism in over 16s: reducing the risk of hospital-acquired deep vein thrombosis or pulmonary embolism. https://www.nice.org.uk/guidance/ng89/resources/venous-thromboembolism-in-over-16s-reducing-the-risk-ofhospitalacquired-deep-vein-thrombosis-or-pulmonary-embolism-pdf-183770

Nguyen T, Truong A, Ngo M, Bui C, et al. (2010). Patients with thrombolysed stroke in Vietnam have an excellent outcome: Results from the vietnam thrombolysis registry. Eur. J. Neurol. 17: 1188-1192.

Palaniswami M and Yan B (2015). Mechanical thrombectomy is now the gold standard for acute ischemic stroke: Implications for routine clinical practice. Interv. Neurol. 4: 18-29.

Pham TL, Blizzard L, Srikanth V, Thrift AG, et al. (2016). Case-fatality and functional status three months after firstever stroke in Vietnam. J. Neurolog. Sci.365: 65-71.

Prabhakaran S, Ruff I and Bernstein RA (2015). Acute stroke intervention: Asystematic review. JAMA. 313: 1451-1462.

Strong K, Mathers C and Bonita R (2007). Preventing stroke: Saving lives around the world. Lancet Neurol. 6: 182-187.

Tirschwell DL, Ton TG, Ly KA, Van Ngo Q, et al. (2012). A prospective cohort study of stroke characteristics, care, and mortality in a hospital stroke registry in Vietnam. BMC Neurol. 12: 150.

Van Exel N, Koopmanschap M, van den Berg B, Brouwer W, et al. (2005). Burden of informal caregiving for stroke patients. Cerebrovasc. Dis. 19: 11-17.

Victor G, Sommer J and Khan FH (2019). 21st century nurse's role in decreasing the rising burden of cardiovascular disease. Anaesth. Pain Int. Care. 2019: 503-510. 
Wang W, Li M, Chen Q and Wang J (2015). Hemorrhagic transformation after tissue plasminogen activator reperfusion therapy for ischemic stroke: Mechanisms, models, and biomarkers. Molec. Neurobiol. 52: 1572-1579.

Watanabe TT, Ichijo M and Kamata T (2019). Uneventful pregnancy and delivery after thrombolysis plus thrombectomy for acute ischemic stroke: Case study and literature review. J. Stroke Cerebrovasc. Dis. 28: 70-75.

Wijdicks E (2006). Practice parameter: Prediction of outcome in comatose survivors after cardiopulmonary resuscitation (an evidence-based review): report of Quality Standards Subcommittee of the American Academy of Neurology. Neurology. 67(2): 203-210.

World Health Organization, Public Health Agency of Canada. (2005). Preventing chronic diseases: A vital investment. Geneva, Ottawa: World Health Organization; Public Health Agency of Canada. 